NASALTm-112964

$$
\begin{array}{r}
1 N-Y \ldots 12 \\
-24 \times 90
\end{array}
$$

\title{
Rare Earth Element Partition Coefficients from Enstatite/Melt Synthesis Experiments
}

Craig S. Schwandt ${ }^{1}$ and Gordon A. McKay ${ }^{2}$

${ }^{1}$ Lockheed Martin, Science, Engineering, Analysis and Test, 2400 Nasa Rd 1, C23, Houston, TX 77058

${ }^{2}$ NASA, Johnson Space Center, SN4, Houston, Texas 77058

\section{October 1997}

Manuscript submitted as a Letter to Geochimica et Cosmochimica Acta 


\begin{abstract}
Enstatite $\left(\mathrm{En}_{80} \mathrm{Fs}_{19} \mathrm{Wo}_{01}\right)$ was synthesized from a hypersthene normative basaltic melt doped at the same time with $\mathrm{La}, \mathrm{Ce}, \mathrm{Nd}, \mathrm{Sm}, \mathrm{Eu}, \mathrm{Dy}, \mathrm{Er}, \mathrm{Yb}$ and $\mathrm{Lu}$. The rare earth element concentrations were measured in both the basaltic glass and the enstatite. Rare earth element concentrations in the glass were determined by electron microprobe analysis with uncertainties less than two percent relative. Rare earth element concentrations in enstatite were determined by secondary ion mass spectrometry with uncertainties less than five percent relative. The resulting rare earth element partition signature for enstatite is similar to previous calculated and composite low-Ca pigeonite signatures, but is better defined and differs in several details. The partition coefficients are consistent with crystal structural constraints.
\end{abstract}




\section{INTRODUCTION}

As part of on-going research into the petrogenesis of basaltic achondrite meteorites, we have recently determined mineral/melt partition coefficients for nine rare earth elements (REE) in enstatite using the percent-level doping technique. Hypersthene normative basaltic glass was concurrently doped with $\mathrm{La}, \mathrm{Ce}, \mathrm{Sm}, \mathrm{Nd}, \mathrm{Eu}, \mathrm{Dy}, \mathrm{Er}, \mathrm{Yb}$, and $\mathrm{Lu}$. Isothermal growth experiments were conducted at $1210^{\circ} \mathrm{C}$ under oxygen fugacity conditions equivalent to the ironwüstite buffer. These conditions produce enstatite crystals $\left(\mathrm{En}_{80} \mathrm{Fs}_{19} \mathrm{Wo}_{01}\right)$ with dimensions of approximately $75 \times 150 \times>1500 \mu \mathrm{m}$. The REE abundances were measured in the pyroxene with a Cameca $4 f$ ion microprobe. REE abundances in the basaltic glass were measured by electron microprobe analysis using the Cameca Camebax and Cameca SX-100 microprobes at the Johnson Space Center. These results provide a REE partition coefficient signature for enstatite. These partition coefficients may be more appropriate for natural enstatite crystals than composite partition coefficients derived for low-Ca pigeonite (e.g., McKay et al., 1986, 1991), because in the present experiments (1) the pyroxene is enstatite rather than pigeonite, and (2) all nine REE were present simultaneously in each charge rather than as individual REE in different charges as in the earlier experiments, and were therefore subject to identical experimental and analytical conditions. This approach provides more assurance of a self-consistent REE partition coefficient signature than calculated or composite signatures derived from several singly doped experiments, because experimental and analytical conditions are sometimes difficult to reproduce exactly, and in singly doped experiments the dopant elements interact in a more simple chemical system. Therefore we present enstatite partition coefficients for nine of the fifteen rare earth elements. 


\section{EXPERIMENTAL PROCEDURE}

Five pure oxides; $\mathrm{SiO}_{2}, \mathrm{Al}_{2} \mathrm{O}_{3}, \mathrm{MgO}, \mathrm{Fe}_{2} \mathrm{O}_{3}$, and $\mathrm{CaO}$ were mixed in appropriate proportions to produce $10 \mathrm{~g}$ of a basaltic glass with a composition similar to the basaltic achondrite meteorites, eucrites, though somewhat more hypersthene normative. The oxide mixture was ground for half an hour under acetone in a motorized mortar and pestle, then melted at $1350{ }^{\circ} \mathrm{C}$ in a large platinum crucible in air for 24 hours. The melt was quenched in de-ionized water and then crushed and ground in the mortar and pestle under acetone for about fifteen minutes to produce a fine glass powder. $\mathrm{Cr}_{2} \mathrm{O}_{3}, \mathrm{TiO}_{2}, \mathrm{La}, \mathrm{Ce}, \mathrm{Nd}, \mathrm{Sm}, \mathrm{Eu}, \mathrm{Dy}, \mathrm{Er}, \mathrm{Yb}$ oxides and $\mathrm{Lu}\left(\mathrm{NO}_{3}\right)_{3}$ were weighed out and added to the appropriate amounts of glass powder and then thoroughly mixed under acetone with a mortar and pestle. Total minor and trace element concentrations were held to less than $4 \mathrm{wt} \%$.

Mineral growth experiments were initiated by suspending $125 \mathrm{mg}$ pressed glass-powder pellets on $3 \mathrm{~mm}$ diameter platinum wire loops in a flowing $\mathrm{CO} / \mathrm{CO}_{2}$ gas-mixing furnace at 1300 ${ }^{\circ} \mathrm{C}$ and iron-wüstite redox conditions for $\mathbf{4 8}$ hours to equilibrate the samples with the fugacity of the experiments and to equilibrate iron exchange with the platinum loop. Approximately $5 \mathrm{wt} \%$ additional $\mathrm{Fe}_{2} \mathrm{O}_{3}$ was added to the original mixture to compensate for iron loss to $\mathrm{Pt}$ in all stages of the experiments. Because of the much higher diffusion rates at $1300^{\circ} \mathrm{C}$ than at the crystallization temperature of $1210^{\circ} \mathrm{C}$, most iron loss occurred during this high temperature equilibration. After equilibration, the samples were air quenched by rapid removal from the furnace. Specific experiments were then initiated by placing a sample back into the furnace at iron-wüstite fugacity conditions, superheating it to $1260^{\circ} \mathrm{C}$ ( $\sim 50$ degrees above the liquidus), 
holding it there for $\sim 4$ minutes, and then dropping the furnace temperature rapidly to $1210^{\circ} \mathrm{C}(2 \pm$ 1 degrees below the liquidus temperature). The samples were then held at constant temperature for 120 hours, and air-quenched by pulling the sample support assembly out of the furnace. This procedure produces samples having less than five percent total crystallization and minimizes nucleation, whereby the few crystals that grow are large enough to analyze without difficulty ( 75 $x 150$ by $>1000 \mu \mathrm{m})$. Nucleation appears to be internal to the sample charge, as the crystals predominantly float freely in the basaltic glass droplet and do not appear to nucleate on the inside surface of the glass sphere or on the wire loop (Lofgren, 1980).

Experiment temperatures are monitored with a thermocouple mounted in the furnace muffle tube approximately three millimeters from the sample. The $\mathrm{Pt}$ and $\mathrm{Pt}-\mathrm{Rh}$ thermocouple is calibrated against the melting point of gold $\left(1064^{\circ} \mathrm{C}\right)$. Temperatures are believed to be accurate within \pm 5 degrees, with relative precision of about \pm 1 degree. The oxygen fugacity is monitored using a solid-state oxygen sensor in a separate reference furnace (Jurewicz et al, 1993) calibrated using a commercially mixed 1:1 $\mathrm{CO}: \mathrm{CO}_{2}$ reference gas. The accuracy for the oxygen fugacity measurements is better than $\pm 0.1 \log$ units, and the experimental oxygen fugacity was equivalent to iron-wüstite minus $0.2 \log$ units $\pm 0.1 \log$ units $\left(\log f \mathrm{O}_{2}=-11.8\right.$ at $\left.1210^{\circ} \mathrm{C}\right)$.

\section{ANALYTICAL PROCEDURES}

Major and minor element compositions of the pyroxene and glass were determined with a five spectrometer Cameca SX-100 electron microprobe. Quantitative analyses utilized natural mineral standards, $15 \mathrm{kV}, 40 \mathrm{nA}$, and the Cameca PAP correction routine (Pouchou and Pichior, 1991). One-sigma counting uncertainties for the major elements are less than one percent of the 
amount present.

Rare earth element concentrations of the enstatite crystals were determined using the University of New Mexico-Sandia National Laboratories, Advanced Materials Laboratory, Cameca $4 \mathrm{f}$ ion microprobe. The $20 \mathrm{nA}$ primary $\mathrm{O}$ minus beam was focused to a $20-25 \mu \mathrm{m}$ beam diameter. The dopant concentrations in these synthetic pyroxenes yield secondary ion count rates high enough to provide theoretical standard deviations of less than one percent. However, due to uncertainties in the standard compositions, the analytical uncertainties are conservatively estimated at less than 5 percent. The nine REE used in these experiments were chosen to avoid both $\mathrm{x}$-ray spectra interferences and isobar interferences during secondary ion mass spectrometry. Ion probe analyses utilized the following isotopes: ${ }^{139} \mathrm{La}^{+},{ }^{140} \mathrm{Ce}^{+},{ }^{146} \mathrm{Nd}^{+},{ }^{147} \mathrm{Sm}^{+},{ }^{151} \mathrm{Eu}^{+},{ }^{153} \mathrm{Eu}^{+}$, ${ }^{163} \mathrm{Dy}^{+},{ }^{167} \mathrm{Er}^{+},{ }^{174} \mathrm{Yb}^{+}$, and ${ }^{175} \mathrm{Lu}^{+}$. Enstatite REE analyses were calibrated against two natural pyroxene standards. The basaltic glass compositions were determined by electron microprobe analysis using a Cameca Camebax and a Cameca SX-100 microprobe, and synthetic glasses containing rare earth elements as standards (Drake and Weill, 1972). The counting uncertainties for the glass analyses are less than two percent.

\section{RESULTS AND DISCUSSION}

The synthesized pyroxene crystals have homogeneous major element compositions consistent with enstatite (Table 1). Longhi and Boudreau (1980) and Longhi (1987) showed that orthoenstatite was stable to "at least as low as $1211^{\circ} \mathrm{C}$ and presumably much lower..." Interestingly, the enstatite crystals of this study are sector zoned with respect to $\mathrm{Al}, \mathrm{Cr}$, and to a lesser extent the REE. Abundances of heavy REE show positive correlations with $\mathrm{Al}$ abundance 
from one sector to another (Fig. 1,2), though the light REE show very little correlation with Al, as indicated by the low value of $\mathrm{R}^{2}$ value for $\mathrm{La}$ as compared with $\mathrm{Lu}$ (Fig. 2). The heavy REE have more mild negative correlations with $\mathrm{Mg}$ and $\mathrm{Fe}$. Detailed discussion regarding the development of minor and trace element sector zoning is in a manuscript in preparation by Schwandt and McKay.

We define the partition coefficients $(D)$ presented here according to the terminology of Beattie et al. (1993), where ${ }^{\text {mineroverelt }} D_{M}={ }^{\text {mineral }} C_{M}{ }^{\text {melt }} C_{M} . M$ represents the cation of interest and $C$ represents the weight fraction of the cation in each respective phase. The $D$ 's determined in each sector for the measured REEs are reported in Table 2. Figure 3 represents a plot of the partition coefficients against the REE's in order of increasing atomic number.

The resulting REE partition coefficient signature (Fig. 3) is similar to the theoretical signature as calculated from pyroxene wollastonite content with the equation of McKay et al. (1986) and to the composite low-Ca pigeonite signature (McKay et al. 1991). However, because more REE were measured, the new partition coefficient pattern is better defined than the older ones, especially for the HREE. The new pattern also differs in important details from the older ones. Compared with the composite pattern from McKay et al. (1991), the new pattern has a steeper slope for the LREE, and a higher $\mathrm{D}_{\mathrm{Sm}} / \mathrm{D}_{\mathrm{Nd}}$ ratio. This may be a result of the difficulties of measuring very low partition coefficient values using the electron microprobe (McKay, 1986). Compared with the pattern calculated using the equation of McKay et al. (1986), the new pattern is steeper overall, and much smoother. This result is not surprising because the calculated pattern in Fig. 3 represents an extrapolation to significantly lower Wo content than experimental 
pyroxenes used by McKay et al. (1986) to parameterize ${ }^{\mathrm{P} /} \mathrm{D}_{\mathrm{REE}}$ as a function of Wo.

The new partition coefficient pattern also shows a significant negative Eu anomaly, indicating that the partition coefficient for $\mathrm{Eu}^{+2}$ is less than that for $\mathrm{Eu}^{+3}$. Of course the size of this Eu anomaly will vary with oxygen fugacity, with the current experiments having been run at fugacities close to IW. Thus, at low $f \mathrm{o}_{2}$, orthopyroxene will have a negative Eu anomaly even if it crystallizes from a melt with chondritic Eu/Sm.

The observed REE partition coefficient signatures are easily rationalized based on crystal structural constraints. The size of the pyroxene M2 site is more flexible than the M1 site, though cations larger than $\mathrm{Ca}$ are not easily incorporated into the structure (Cameron and Papike 1981). Therefore, as the light REE are significantly larger in ionic size than the heavy REE it is logical that the light REE are depleted in enstatite relative to the heavy REE. The presence of a negative $\mathrm{Eu}$ anomaly indicates that the larger ionic radius of $\mathrm{Eu}^{+2}(1.25 \AA$ in eight-fold coordination, vs. $1.07 \AA$ for $\mathrm{Eu}^{+3}$, Shannon, 1976) must make substitution more difficult than for $\mathrm{Eu}^{+3}$ even though the latter requires a charge-balancing coupled substitution.

Based on pyroxene compositions from lunar and meteoritic basaltic rocks, Papike (1980) identified a few primary substitution mechanisms for minor elements in pyroxene: 1) ${ }^{\mathrm{v}} \mathrm{Al}^{3+}+$ ${ }^{\mathrm{NV}} \mathrm{Al}^{3+}$ for ${ }^{\mathrm{V}} \mathrm{Mg}^{2+}+{ }^{\mathrm{N}} \mathrm{Si}^{4+}$. 2) ${ }^{\mathrm{V}} \mathrm{Cr}^{3+}+{ }^{\mathrm{NV}} \mathrm{Al}^{3+}$ for ${ }^{\mathrm{VI}} \mathrm{Mg}^{2+}+{ }^{\mathrm{NV}} \mathrm{Si}^{4+}$. 3) ${ }^{\mathrm{V}} \mathrm{Ti}^{4+}+2^{\mathrm{NV}} \mathrm{Al}^{3+}$ for ${ }^{\mathrm{VI}} \mathrm{Mg}^{2+}+$ ${ }^{\mathrm{rV}} \mathrm{Si}^{4+}$. Similarly, relative to the sector zoning in our synthetic pyroxenes, $\mathrm{Mg}$ and $\mathrm{Si}$ show strong inverse correlations and $\mathrm{Cr}$ a strong normal correlation with $\mathrm{Al}$ concentration. This suggests the same coupled substitution mechanisms are important. Incorporation of the REE into the enstatite structure must also be occurring via a similar coupled substitution $\left({ }^{\mathrm{V}} \mathrm{REE}^{3+}+{ }^{\mathrm{IV}} \mathrm{Al}^{3+}\right.$ for ${ }^{\mathrm{VI}} \mathrm{M}_{2}{ }^{2+}+$ 
${ }^{\mathrm{IV}} \mathrm{Si}^{4+}$ ) because REE concentrations in the enstatite correlate positively with $\mathrm{Al}$ concentration (at least for the HREE, Fig. 2) and correlate negatively with the typical M2 cations. The REE correlations are strongest with $\mathrm{Al}$ and only moderate relative to the $\mathrm{M} 2$ cations individually. Therefore this REE partitioning behavior suggests that the incorporation of impurity cations, such as the REE, in the enstatite crystal structure is at least partly controlled by the substitution of $\mathrm{Al}$ for $\mathrm{Si}$ in the tetrahedral sites. Moreover, these results suggest there is an additional charge compensation involving the larger impurity cations in the octahedral M2 site. The mechanism behind this observation and investigation of the mechanisms leading to the development of sector zoning of minor and trace elements is explored in depth in a manuscript in preparation by Schwandt and McKay.

\section{CONCLUSION}

We have determined nine REE partition coefficients and the resulting REE partitioning signature for enstatite synthesized from a hypersthene normative basaltic melt. We believe these partition coefficients provide the most complete and reliable experimentally determined partition coefficient pattern currently available for orthopyroxene. These partition coefficients are useful for research on the petrogenesis of basaltic achondrite meteorites and terrestrial mantle materials. In addition, the results also provide clues about mechanisms resulting in the incorporation of impurity cations into the pyroxene crystal structure.

\section{ACKNOWLEDGMENTS}

This research was carried out while the first author held a National Research CouncilJohnson Space Center Research Associateship. The work was also partially supported by NASA 
RTOP 152-12-40-21. We appreciate access to the University of New Mexico-Sandia National Laboratories Ion Microprobe Facility. We thank Grant Fowler and S. Vincent Yang for analytical assistance with the UNM-Sandia Ion Microprobe and the JSC Electron Microprobe respectively.

\section{REFERENCES}

Beattie P., Drake M., Jones J., Leeman W., Longhi J., McKay G., Nielsen R., Palme H., Shaw D., Takahashi E., and Watson B. (1993) Terminology for trace-element partitioning. Geochim. Cosmochim. Acta 57, 1605-1606.

Cameron M. and Papike J.J. (1981) Structural and chemical variations in pyroxenes. Amer. Mineral. 66, 1-50.

Drake M.J. and Weill D.F. (1972) New rare earth element standards for electron microprobe analysis. Chem. Geol. 10, 179-181.

Jurewicz A.J.G., Williams R.J., Le. L., Wagstaff J., Lofgren G., Lanier A., Carter W. and Roshko A. (1993) Technical update: JSC system using a solid electrolytic cell in a remote location to measure oxygen fugacities in $\mathrm{CO} / \mathrm{CO}_{2}$ controlled-atmosphere furnaces. NASA Technical Memorandum 104774.

Lofgren G.E. (1980) Experimental studies on the dynamic crystallization of silicate melts. In Physics of Magmatic Processes (ed. R.B. Hargraves), Chap. 11, pp. 487-552. Princeton University Press.

Longhi J. (1987) Liquidus equilibria and solid solution in the system $\mathrm{CaAl}_{2} \mathrm{Si}_{2} \mathrm{O}_{8}-\mathrm{Mg}_{2} \mathrm{SiO}_{4}$ $\mathrm{CaSiO}_{3}-\mathrm{SiO}_{2}$ at low pressure. Amer. J. Sci. 287, 265-331.

Longhi J. and Boudreau A.E. (1980) The orthoenstatite liquidus field in the system forsterite10 
diopside-silica at one atmosphere. Amer. Mineral. 65, 563-573.

McKay G.A. (1986) Crystal/liquid partitioning of REE in basaltic systems: Extreme fractionation of REE in olivine. Geochim. Cosmochim. Acta 50, 69-79.

McKay G., Wagstaff J., and Yang S.-R. (1986) Clinopyroxene REE distribution coefficients for shergottites: The REE content of the Shergotty melt. Geochim. Cosmochim. Acta 50, 927-937.

McKay G., Le L., and Wagstaff J. (1991) Constraints on the origin of the mare basalt europium anomaly: REE partition coefficients for pigeonite. Lunar Planet. Sci. Conf. XXII, 883884 (abstr.).

Papike J.J. (1980) Pyroxene mineralogy of the moon and meteorites. In Pyroxenes (ed. C.T. Prewitt) Rev. Mineral., 7, 495-525. Mineralogical Society of America.

Pouchou J. and Pichior F. (1991) Quantitative analysis of homogeneous or stratified microvolumes applying the model "PAP". In Electron Probe Quantitation (ed. K.F.J. Heinrich and D.E. Newbury), pp. 31-75. Plenum.

Shannon R. D. (1976) Revised values of effective ionic radii and systematic studies of interatomic distances in halides and calcogenides. Acta Crsyt. A32, 751-767. 
Table 1. Major element compositions determined by electron microprobe analysis. Trace element values in glass determined by electron microprobe analysis. Trace element values in enstatite obtained by SIMS. Column numbers match SIMS analysis spots shown in Figure 1.

\begin{tabular}{|c|c|c|c|c|c|c|}
\hline & Glass & Enstatit & & & & \\
\hline Wt \% & & 1 & 2 & 3 & 4 & 5 \\
\hline $\mathrm{SiO}_{2}$ & 53.31 & 52.96 & 53.26 & 53.79 & 53.33 & 53.44 \\
\hline $\mathrm{Al}_{2} \mathrm{O}_{3}$ & 15.07 & 3.29 & 3.42 & 2.52 & 3.30 & 3.01 \\
\hline $\mathrm{MgO}$ & 8.06 & 28.37 & 28.49 & 28.66 & 28.53 & 28.35 \\
\hline $\mathrm{FeO}$ & 12.50 & 12.64 & 12.84 & 12.99 & 12.77 & 12.90 \\
\hline $\mathrm{CaO}$ & 6.93 & 0.63 & 0.64 & 0.63 & 0.64 & 0.64 \\
\hline $\mathrm{TiO}_{2}$ & 0.22 & 0.05 & 0.05 & 0.05 & 0.06 & 0.06 \\
\hline $\mathrm{Cr}_{2} \mathrm{O}_{3}$ & 0.13 & 0.92 & 0.98 & 0.78 & 0.86 & 0.84 \\
\hline \multicolumn{7}{|l|}{ ppm: } \\
\hline $\mathrm{La}$ & 5012 & 1.99 & 1.62 & 1.43 & 2.82 & 2.65 \\
\hline $\mathrm{Ce}$ & 6118 & 6.72 & 5.74 & 4.74 & 7.5 & 8.49 \\
\hline $\mathrm{Nd}$ & 4322 & 18.5 & 16.18 & 12.56 & 17.68 & 21.39 \\
\hline Sm & 4831 & 59.6 & 54.0 & 40.0 & 57.5 & 65.6 \\
\hline Eu & 4738 & 21.9 & 21.3 & 15.8 & 21.7 & 19.8 \\
\hline Dy & 3236 & 171 & 175 & 121 & 173 & 178 \\
\hline $\mathrm{Er}$ & 3297 & 305 & 320 & 225 & 323 & 317 \\
\hline $\mathrm{Yb}$ & 3664 & 381 & 412 & 294 & 419 & 394 \\
\hline$\underline{\mathbf{L u}}$ & 4641 & 478 & 533 & 384 & 532 & 503 \\
\hline \multicolumn{7}{|c|}{ Mole Fraction: } \\
\hline$f e^{\prime}$ & 0.46 & 0.19 & 0.20 & 0.20 & 0.20 & 0.20 \\
\hline Wo & & 0.012 & 0.012 & 0.012 & 20.012 & 20.013 \\
\hline En & & 0.79 & 0.79 & 0.79 & 0.79 & 0.80 \\
\hline
\end{tabular}


Table 2. Rare earth element partition coefficients. Column numbers match SIMS analysis spots shown in Figure 1. Uncertainties

less than $5 \%$.

\begin{tabular}{lccccc}
\hline & 1 & 2 & 3 & 4 & 5 \\
$\mathrm{La}$ & 0.0004 & 0.0003 & 0.0003 & 0.0006 & 0.0005 \\
$\mathrm{Ce}$ & 0.0011 & 0.0009 & 0.0008 & 0.0012 & 0.0014 \\
$\mathrm{Nd}$ & 0.0043 & 0.0037 & 0.0029 & 0.0041 & 0.0049 \\
$\mathrm{Sm}$ & 0.0123 & 0.0112 & 0.0083 & 0.0119 & 0.0136 \\
$\mathrm{Eu}$ & 0.0046 & 0.0045 & 0.0033 & 0.0046 & 0.0042 \\
$\mathrm{Dy}$ & 0.052 & 0.054 & 0.037 & 0.053 & 0.054 \\
$\mathrm{Er}$ & 0.092 & 0.097 & 0.069 & 0.098 & 0.096 \\
$\mathrm{Yb}$ & 0.104 & 0.112 & 0.080 & 0.114 & 0.107 \\
$\mathrm{Lu}$ & 0.103 & 0.114 & 0.082 & 0.114 & 0.108 \\
\hline
\end{tabular}




\section{Figure Captions:}

1. Digital map of $\mathrm{Al}$ concentration. Bright indicates high $\mathrm{Al}$ concentration and dark indicates low Al concentration. Enstatite crystal with sector zoning of $\mathrm{Al}$ surrounded by basaltic glass. Circles outline ion microprobe analysis locations. Analyses 1 and 5 are in $\{100\}$ sectors, 2 and 4 are in $\{010\}$ sectors and 3 is in a portion of $\{001\}$ sector overlapped by a low Al zone that is the result of growth twinning.

2. Plot of $\mathrm{Al}_{2} \mathrm{O}_{3}$ wt \% versus the REE concentration (ppm) showing the correlation of the REE with $\mathrm{Al}$. Correlation Coefficients $\left(\mathrm{R}^{2}\right)$ are given for $\mathrm{La}$ and $\mathrm{Lu}$, and indicate a declining correlation with increasing cationic size, i.e. lighter REE.

3. Partition coefficient versus atomic number plot reveals the rare earth element partitioning signature for enstatite. The field represents the variation of the partition coefficients as a function of the sector zoning. The experimental signature is compared with a pattern calculated from the variation of partition coefficients with the wollastonite content of synthetic shergottite pyroxenes (McKay et al., 1986) and a composite low-Ca pigeonite pattern from several experiments doped with single REE (McKay et al., 1991). 


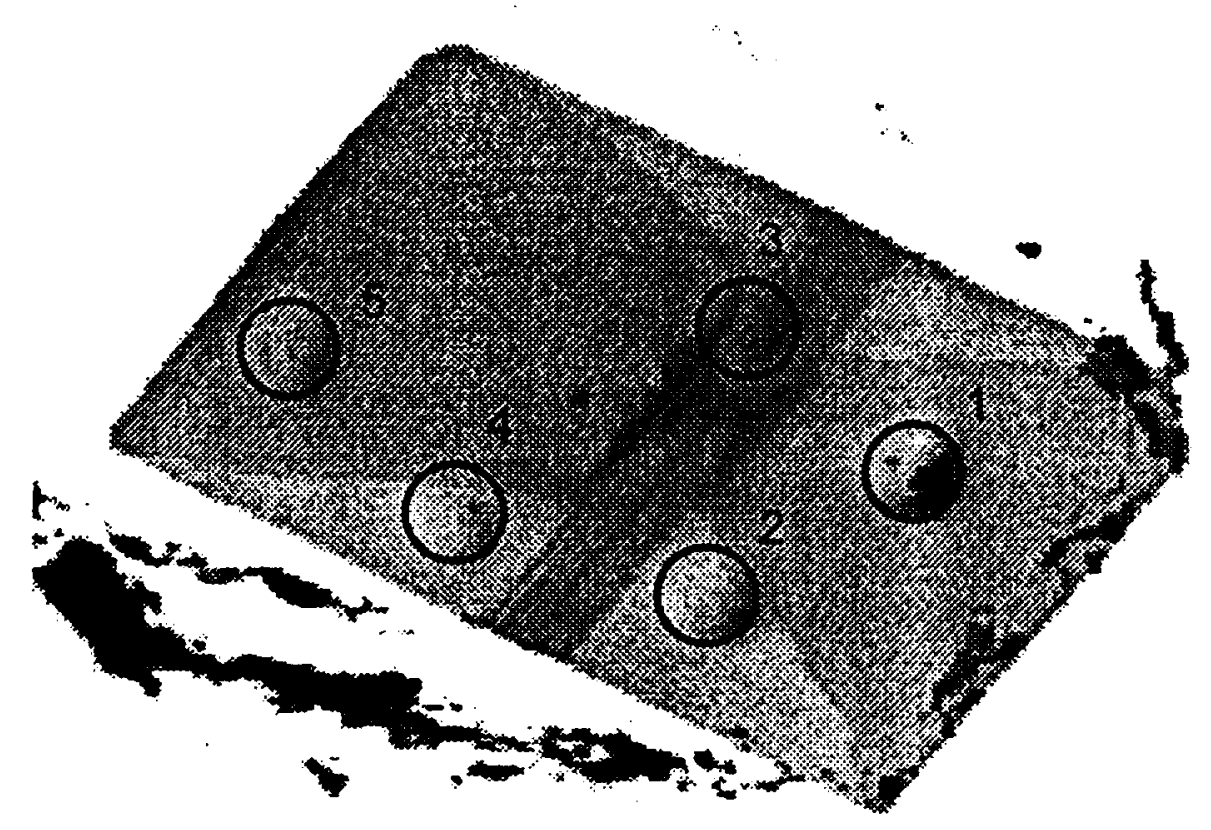

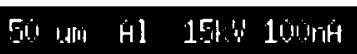

Figure 1 


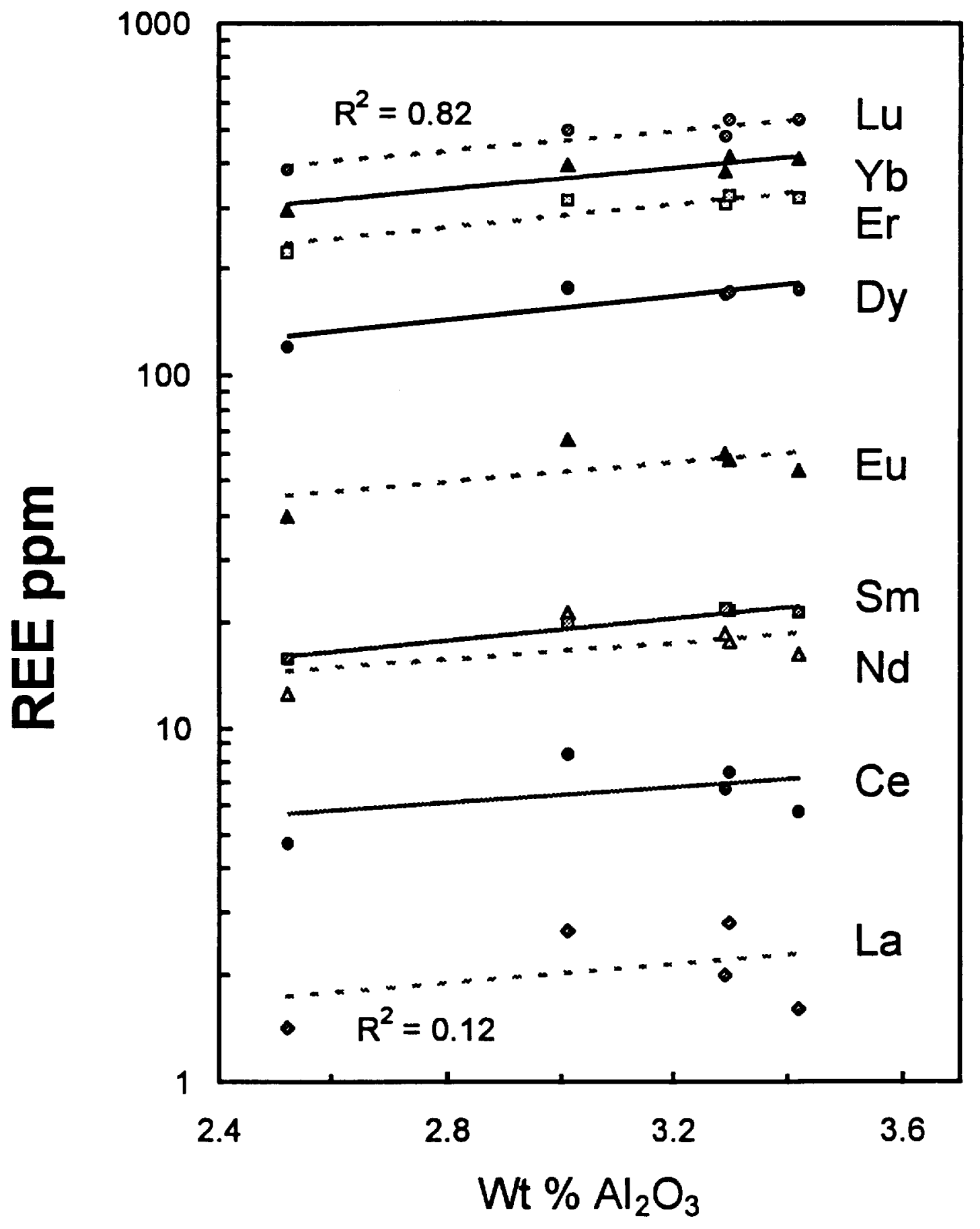

Figure 2 


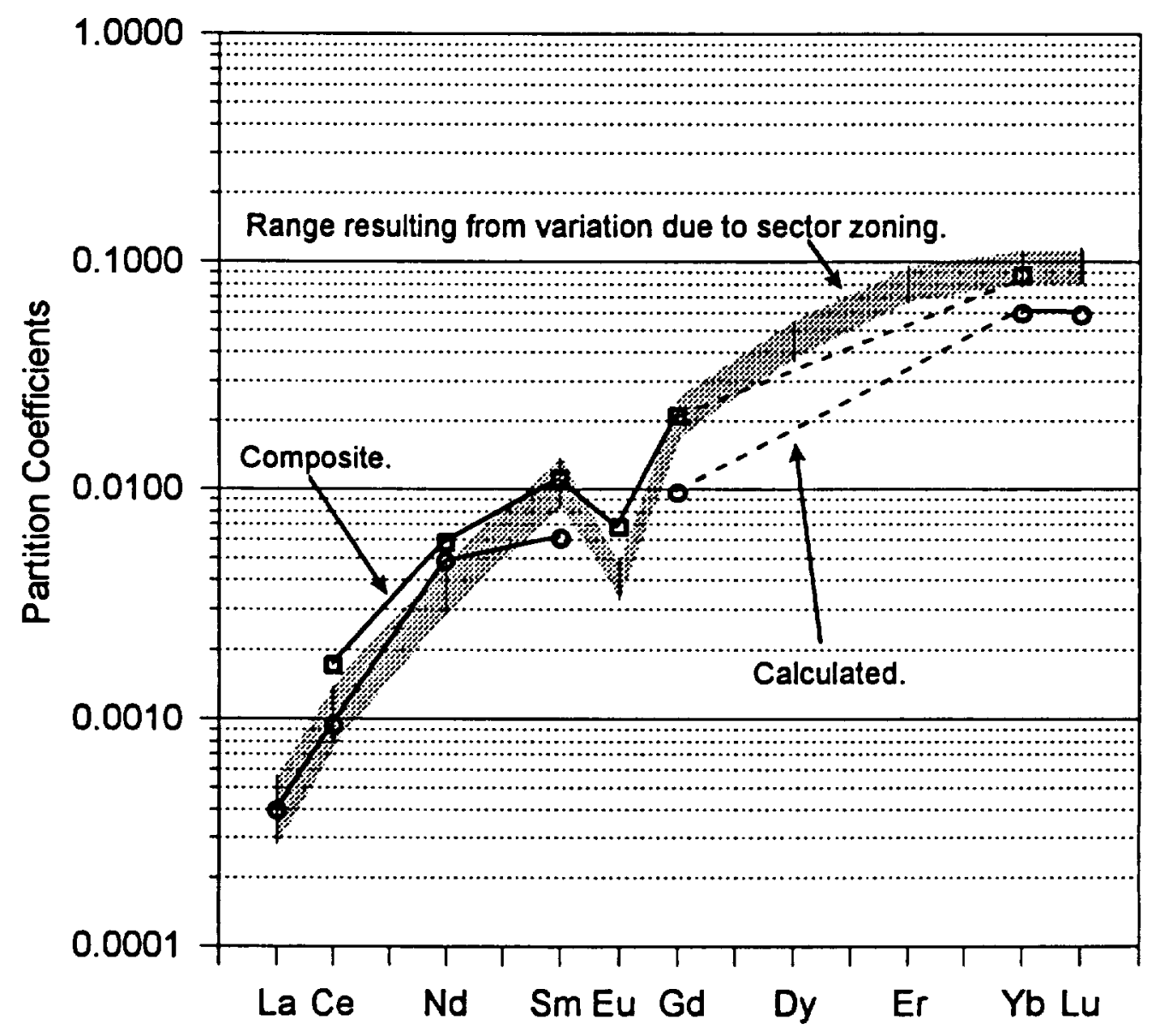

Figure 3 